\title{
OS FRUTOS DE MAIO DE 1968 - O Grito dos Silenciados
}

\author{
José Eustáquio. Romão1 \\ Universidade Nove de Julho-UNINOVE. \\ São Paulo-Brasil
}

Recepción: 30/05/2008

Evaluación 01/06- 15/09/2008

Aceptación: 29/09/2008

Articulo de Reflexión

\section{RESUMEN}

Examinaré, aunque sumariamente, lo que ocurrió hace 40 años para verificar si, verdaderamente, hubo cambios profundos en la dinámica del mundo, en general y, en especial, las teorías del conocimiento hegemónicos en Brasil, en ese cuasi medio siglo. Si embargo, los años 60 del siglo XX, considerados como la "década que todo cambia" y 1968 como el "año que [aun] no se acabo" me perece pertinente y relevante examinar si hubo cambios en la geopolítica del conocimiento y de que manera estos cambios afectó la educación brasileña, en especial la superior. Tomamos aquí la expresión geopolítica del conocimiento en el sentido de investigar e identificar lugares de enunciación científica diferentes de los tradicionales y hegemónicos entre nosotros. Buscar las expresiones de racionalidades que fueron silenciadas por año y siglos, no por la superioridad gnoseológica de sus silenciadores, pero por las correlaciones del poder. Con toda forma de poder se ha contestado en la década de los 60 , es posible que ahí tenga potencializando las diversas "epistemologías" que, hoy, defienden la reconstitución y búsqueda de racionalidades que fueron calladas.

Palabras Claves: Movimientos estudiantiles, Ideologías, Racionalidades contra-hegemónicas.

\footnotetext{
${ }^{1}$ Graduado em História, pela Universidade Federal de Juiz de Fora (1970) e Doutorado em Educação (1996), pela Universidade de São Paulo. Atualmente, é professor do curso de Mestrado em Educação, na Universidade Nove de Julho (UNINOVE), em São Paulo, onde coordena o Grupo de Pesquisa «Culturas e Educação». É professor visitante da Universidade Lusófona de Humanidades e Tecnologias (ULHT), de Lisboa, Portugal.
} 


\title{
THE FRUIT OF THE MAY (1968): THE CRY OF SILENCED
}

\author{
José Eustáquio. Romão \\ Universidade Nove de Julho - UNINOVE. \\ São Paulo-Brasil
}

\begin{abstract}
Look, albeit briefly, what happened 40 years ago to see if there actually were profound changes in the dynamics of the world in general and especially in hegemonic theories of knowledge in Brazil, in almost half a century. And since the 60 s of the twentieth century, they were regarded as "the decade that changed everything", and 1968 as the "year that [still] not over" seems to me pertinent and relevant to examine a concern: if there was change in the geopolitics of knowledge and if this change affected the way of education in Brazil, especially higher education. We take the term geopolitics of knowledge in order to search for and identify places of enunciation of scientific and traditional hegemony among us. I search the terms of rationales that have been silenced for years, for centuries, not by the superiority of their "gnosiologica" silencers, but by correlation of power. As any form of power was challenged in the 60s, it might have had several changes in the "epistemologies" that now advocate the restoration and consideration of rationales that have been gagged.
\end{abstract}

Key Words: Student Movements, Ideologies, rationalities antihegemonic

\section{INTRODUÇÃO}

Antes de entrar no objeto deste texto - do qual fui e ainda sou, em parte, testemunha ocular-, convém esclarecer alguns aspetos a respeito do enfoque que lhe será dado. E a intenção deste esclarecimento não é a de convencer a quem quer que seja, mas de explicitar as minhas opções ideológicas, exatamente para permitir ao leitor maior objetividade para aderir, ou não, às conclusões a que cheguei.

As narrativas de história vivida sempre correram, e correm, dois tipos de risco: de um lado, a tentação apologética, se os acontecimentos beneficiaram o narrador; de outro, a radicalização da crítica, se ele foi prejudicado pelos mesmos acontecimentos. Sem falar nas traições da memória, no contexto da chamada "história oral". 
Os defensores do positivismo histórico ${ }^{2}$ chegam mesmo a negar a possibilidade da História Contemporânea, porque, segundo eles, somente pode ter o nome de ciência histórica aquela narrativa "distanciada" do narrado por, no mínimo, uma geração, para que se possam examinar os fatos "objetivamente", "como coisas" como queria Durkheim. ${ }^{3}$ Afirmam que, ao contrário, acontecimentos coetâneos ao analista lhe possibilitam, no máximo, "palpites políticos”, sem aquela objetividade cobrada pela elaboração científica. Esta mesma corrente de pensamento considera que, para que haja História (com "H” maiúsculo), isto é, ciência histórica, é necessário que as fontes sejam documentos escritos. Sem documento escrito, "pas d’histoire”" (não há História), dizem os defensores da Razão Positivista, ${ }^{4}$ numa clara defesa da trajetória histórica das elites. De fato, apenas as elites produzem documentos escritos sobre suas próprias biografias pessoais e coletivas. Já a história oral, aquela predominante entre as camadas subalternizadas, pertenceria ao campo das meras opiniões, dos palpites políticos, quando muito, da pré-história.

Ora, o documento escrito - produzido por alguém que foi contemporâneo aos acontecimentos registrados - não estaria sujeito também à crítica idêntica, por sua carga de subjetividade, já que seu autor viveu os fatos que narra, tendo sido beneficiado ou prejudicado por eles? A diferença de objetividade estaria apenas no registro escrito do testemunho ocular?

Não me filio a tal corrente historiográfica, mas àquela que considera todas as alocuções como resultados de análises resultantes de pontos de vista diferentes, portanto carregadas de escolhas e de condicionamentos sociais e pessoais, seja pela inserção em contextos classistas, seja por trajetórias específicas de vida. Nesta perspectiva, toda e qualquer afirmação, mesmo as científicas, constituem enunciações a partir de pontos (histórico-sociais) de observação singulares, estando, assim, carregadas de conotações ideológicas. ${ }^{5}$ A partir deste viés analítico, o "distanciamento" epistemológico é impossível, a neutralidade é um mito e toda afirmação, pelo menos nas ciências sociais, denotam em um nível e conotam em outro. Como Eliseo Verón (1972), ${ }^{6}$ entendo que mensagens puramente

\footnotetext{
${ }^{2}$ Não nos referimos, aqui, ao Positivismo (com maiúscula) em sentido estrito, mas a todas as correntes científicas que acreditam na possibilidade da neutralidade axiológica nas ciências sociais.

3 DURKHEIM, Émile. (1977): As regras do método sociológico, Tradução Maria Isaura Pereira de Queiroz, São Paulo: Nacional.

4 Que preferimos denominar Razão Estrutural, para se evitar a confusão de ela se limitar aos seguidores mais diretos de Auguste Comte. Incluímos nesta corrente todos os pensadores que concebem ciência como uma estrutura, como uma disciplina, como um quadro acabado de leis, axiomas, postulados e interpretações objetivas da realidade. ${ }^{5}$ Ideologia entendida, aqui, como visão social de mundo e, não, como falsificação da realidade, ainda que as visões sejam mais ou menos distorcidas pelos interesses de quem enuncia.

${ }^{6}$ Verón propõe três momentos da análise: sintática, semântica e pragmática. Os dois primeiros podem ser resumidos em um só, sintático-semântico, porque diz respeito ao discurso in praesentia, e a pragmática seria a análise contextual.
} 
denotativas pertencem ao mundo da ficção e que, para sua compreensão em extensão e em profundidade, é necessário fazer a análise da literalidade do discurso para, em seguida, remetê-lo às condições histórico-sociais de sua produção, disseminação e recepção. Além disso, em decorrência desta convicção gnosiológica, quando desenvolvo ciência, escolho e assumo idéias e posições classistas específicas, não sendo possível fazer assepsia ideológica de partida... nem de chegada. Contudo, entendo que é possível diminuir o efeito ideológico no interlocutor, explicitando as opções feitas. Dessa forma, é mais objetivo, é mais científico, quem proclama suas opções ideológicas, do que quem as esconde por trás de uma pseudo-neutralidade objetiva.

Diante destas considerações iniciais, examinarei, ainda que sumariamente, o ocorrido há 40 anos atrás para verificar se, de fato, houve mudanças profundas na dinâmica do mundo, em geral e, em especial, nas teorias do conhecimento hegemônicas no Brasil, neste quase meio século. E já que os anos 60 do século XX foram considerados como a "década que mudou tudo" e 1968 como o "ano que [ainda] não acabou", 8 perece-me pertinente e relevante examinar um tema: se houve mudança na geopolítica do conhecimento e de que maneira esta mudança afetou a educação no Brasil, especialmente a educação superior. Tomamos a expressão geopolítica do conhecimento no sentido que lhe emprestou Walter Mignolo, ${ }^{9}$ ou seja, pesquisar e identificar lugares de enunciação científica diferentes dos tradicionais e hegemônicos entre nós. Buscar estes loci epistemológicos não significa pesquisar formulações inéditas, mas expressões de racionalidades ${ }^{10}$ que foram silenciadas durante anos, durante séculos, não pela superioridade gnosiológica de seus silenciadores, mas por correlações de poder. Como toda forma de poder foi contestada na década de 1960, é possível que aí tenham se potencializado as diversas "epistemologias" que, hoje, defendem a reconstituição e a tomada em consideração de racionalidades que foram amordaçadas.

Por fim, cabe salientar nesta introdução que, para não ficar no nível meramente descritivo das recordações das experiências existenciais, terei de fazer uma reconstituição histórica do período, combinando lembranças e exame de fontes históricas, fazendo algumas incursões nos anos mais imediatos ao pós-guerra (1939-1945).

\footnotetext{
${ }^{7}$ VEJA. Os anos 60: a década que mudou tudo. São Paulo: Abril, s/d (publicação editada em fascículos).

8 Título do livro do jornalista Zuenir Ventura (1988).

${ }^{9}$ MIGNOLO. (2003):Walter. Histórias locais/projetos globais: colonialidade, saberes subalternos e pensamento liminar. Tradução Solange Ribeiro de Oliveira, Belo Horizonte, Ed. UFMG.

10 Às diversas perspectivas gnosiológicas e epistemológicas, isto é, às diversas racionalidades, hegemônicas e contra-hegemônicas, daremos o nome de Razões.
} 


\section{1. $O$ contexto dos anos 60}

Multinacionais, bipolaridade política, Guerra Fria, ${ }^{11}$ corridas armamentista, nuclear e espacial, Revolução Cubana, guerrilha, descolonização africana, Vietnã, Primavera de Praga e utopia revolucionária são alguns dos diversos temas que vêm à cabeça de qualquer pessoa que se debruça sobre anos 60. São ainda muito vivos e presentes os ecos desses temas na atualidade. Também fortemente presentes são as sonoridades do rock e da música de protesto; as imagens da Nowvelle Vague, com os Cabiers du Cinéma, e do Cinema Novo, especialmente com Deus e o Diabo na Terra do Sol, de Glauber Rocha, e o pensamento da Escola de Frankfurt, particularmente para a época, o de Herbert Marcuse. Cada um desses fatos, processos e temas, que marcaram tão profundamente a juventude de minha geração, merece um comentário breve, excetuando a "utopia revolucionária" que constitui o tema central deste trabalho.

\section{Capitalismo Transnacional}

$\mathrm{Na}$ década de 1960, o Capitalismo já insinuava o processo de globalização do capital, uma vez que as duas guerras inter-imperialistas ameaçaram-no estruturalmente, chegando mesmo, em 1929, a se pensar no seu desaparecimento e substituição por outro modo de produção. Além disso, o longo conflito - na verdade as I e a II Guerra constituíram um único conflito com uma trégua entre 1914 e 1939 - havia terminado com um saldo monumental de sacrifício de vidas humanas e de uma gigantesca alteração da correlação de forças imperiais. Após a I Guerra, desmorona-se o Império Austro-Húngaro, e os re-arranjos que os vitoriosos fizeram no mapa europeu criaram uma bomba de efeito retardado que explodiria em 1929. Nesse período emergiram potências extra-européias: Japão e Estados Unidos que, na disputa de mercados coloniais com os antigos impérios europeus, arrastariam a humanidade para uma nova conflagração mundial. Alemanha, Itália e Japão, derrotados, saíam da II Guerra na condição de ex-potências colonizadas. Inglaterra e França, apesar de vitoriosas, também estavam com seus campos talados e a maioria de suas cidades destruídas. Os Estados Unidos e a URSS, apesar de terem sofrido combates em seus próprios territórios ${ }^{12}-$ e a última teria enfrentado a mais sangrenta das batalhas da II Guerra, em Stalingrado-, emergiram como potências.

\footnotetext{
11 Que preferimos grafar com maiúsculas, porque se referem ao fenômeno político específico de conflito não aberto entre Estados Unidos e URSS, ainda que generalizado em suas conseqüências.

12 Considerando que os norte-americanos sofreram o ataque a Pearl Harbour.
} 
Do lado do Capitalismo, a acumulação só se tornaria possível a partir da mundialização do mercado, no chamado "Capitalismo de Organização". As crises periódicas que Marx previra eram compensadas por procedimentos, nem sempre legais, em outras partes do mundo, onde estavam instaladas das grandes empresas, que tinham descaracterizado seu caráter nacional. Agora, escancaradamente o capital se revelava sem compromisso com qualquer corde bandeira, por meio das chamadas multinacionais. ${ }^{13}$ Aliás, ele nunca assumira compromissos com qualquer nacionalidade, embora o nacionalismo seja invenção sua - uma verdadeira contrafação para substituir o coletivo de classe -, com a finalidade de evitar o "motor da história" e facilitar a acumulação, nos séculos anteriores. Entretanto, ele chegara a uma fase em que esse disfarce não era mais necessário. A tendência estrutural do Capitalismo de domínio autoritário de todo o Globo se tornara realidade, revelando que o antagonismo não se dá entre nações, mas entre as classes dominantes de um país, aliadas com seus pares de outro país, contra as classes dominadas de qualquer um deles. Ficava, assim, clara e oportuna o alerta de Marx sobre ser a luta de classes o motor da História e, não qualquer outra institucionalidade criada pela ideologia burguesa.

\section{Bipolaridade Política e Guerra Fria}

As incertezas do longo conflito mundial - considerando-se como datas limites 1914 e 1945, com a trégua do entre guerras - tinham se dissipado no final da década de 50, embora o decênio tenha sido marcado pela sangrenta Guerra da Coréia, que resultou na divisão do país em Norte e Sul, em 1954. O conflito fora uma espécie de primeira demonstração do que seria a Guerra Fria, que estabeleceu, definitivamente, a bipolaridade entre a "Cortina de Ferro" e a "Cortina de Dólar". Aliadas apenas até a derrota final do Japão, Estados Unidos e Rússia tornaram-se inimigos encarniçados depois do Julgamento de Nuremberg. Nascia a famosa bipolaridade política, com o socialismo stalinista de um lado, com vários países girando como satélites em torno da União das Repúblicas Socialistas Soviéticas(URSS), e o capitalismo burguês, coordenado pelos Estados Unidos, também com várias nações dependentes, orbitando sua área de influência.

\section{Corridas Armamentista, Nuclear e Espacial}

O precário equilíbrio político acabou por gerar uma verdadeira corrida armamentista, já que cada um dos dois "grandes", não sabia o que o outro havia alcançado em termos de poder de fogo e toca a desenvolver armas

\footnotetext{
13 O termo «multinacional» foi formulado pelo economista norte-americano David Lilienthal, em 1960. Entretanto, o nome mais apropriado seria «transnacionais», dado seu não compromisso explícito com qualquer nação.
} 
cada vez mais letais. É evidente que este verdadeiro campeonato de violência potencial alavancava o avanço econômico, uma vez que as demandas da indústria bélica implicavam gigantescos investimentos de recursos materiais, humanos e tecnológicos. É neste sentido que a "corrida tecnológica" foi fator e resultado da disputa bipolar. E o que fazer com os gigantescos estoques de armamento? Eles eram escoados para os conflitos localizados, estimulados pelos “dois grandes", que temiam o confronto direto. Por isso, os anos 60 do século passado iniciaram-se com o otimismo alimentado pela prosperidade que se desenvolvia dos dois lados do campo de confronto.

A década de 60 está inserida no que um economista chamou "a longa prosperidade do pós-guerra", quando um ritmo acelerado de crescimento econômico atingiu tanto o mundo capitalista quanto o mundo dito socialista. Para o sistema capitalista foi o período de crescimento mais longo de sua história: a partir da Segunda Guerra e durante quase trinta anos nenhuma crise econômica séria ocorreu em termos mundiais.

O pior da corrida armamentista é que ela desencadeou a corrida nuclear, ou seja, uma desabalada correria pela produção de artefatos bélicos nucleares, ou seja, baseados no imenso poder e destruição da fissão do átomo. Por isso, quando em 1963, Estado Unidos, União Soviética e Inglaterra assinaram o Tratado de Não-Proliferação de Testes Nucleares, ninguém recuperou a tranqüilidade, porque os testes subterrâneos continuavam liberados e a China e a França se recusaram a assiná-lo. Cada conquista do adversário gerava um frisson do outro lado e, conseqüentemente, um novo esforço da metrópole e dos satélites para superarem o avanço registrado. Neste sentido, a corrida espacial seguiu a mesma dinâmica.

Quando os russos puseram o primeiro satélite pilotado por seres humanos na órbita da Terra, em 12 de abril de 1961, e o soviético Yuri Gagarin fez o primeiro vôo orbital tripulado a bordo da Vostok. 1, os norteamericanos entraram em pânico. Daí seguiu-se uma verdadeira loucura na órbita da Terra:

O astronauta norte-americano Alan Shepard Jr., a bordo da Mercury 3, faz um vôo sub-orbital, em 5 de maio do mesmo ano.

Em 1962, John Glenn faz o primeiro vôo orbital tripulado norteamericano.

${ }^{14}$ Confira PAES SIMÕES, Maria Helena. (1992): A década de 60: rebeldia, contestação e repressão política. São Paulo: Ática, p. 11. 
Em 1965, o soviético Alexsei Leonov é o primeiro homem a sair de uma nave Voskhod 2 para o espaço, aí permanecendo por 12 minutos; o norte-americano Edward White II sai de sua nave, a Gemini 4, e permanece 20 minutos no espaço.

Em 1968, a nave norte-americana Apollo 8 faz o primeiro vôo tripulado na órbita lunar.

No ano seguinte, a Apollo 11 é a primeira nave tripulada a descer na Lua; dois de seus três tripulantes, Neil Armstrong e Edwin Aldrin, pisam, pela primeira vez, o solo lunar.

Em 1971 é lançada a primeira estação espacial orbital, a Salyut 1. A nave Soyuz 10, com três astronautas, faz a primeira manobra de acoplamento de uma nave à estação.

Em 1973, é lançada a primeira estação orbital norte-americana, a Skylab.

Dois anos depois, é realizada a primeira experiência espacial conjunta dos EUA e URSS, com o acoplamento das naves Apollo 18 e Soyuz 19.

Em 1978, o ônibus espacial Columbia inaugura nova fase da exploração espacial com naves capazes de fazer sucessivas viagens entre a Terra e o espaço.

Em 1984, o astronauta norte-americano Bruce McCandless é o primeiro homem a voar livremente no espaço. Com uma mochila propulsora nas costas, ele se afasta até $100 \mathrm{~m}$ da nave Challenger.

Em 1986, os soviéticos Leonid Kizim e Vladimir Soloviov saem da Mir no módulo de transporte Soyuz T-15, percorrem 3 mil km, fazem acoplagem com a Salyut-7 e, depois, regressam à Mir.

Em 1991, a astronauta norte-americana Shannon Lucid permanece 530 horas no espaço.

No ano seguinte, a nave russa Soyuz TM-14, com dois astronautas russos e um alemão, resgata o astronauta Serguei Krikalev da estação espacial Mir. Permanecem por dez meses no espaço. O ônibus espacial norte-americano Atlantis lança o laboratório espacial europeu Eureca-1.

Em 1993, o Columbia lança o laboratório alemão Spacelab D-2. 
Além de orbitar a Terra e chegar até à Lua, as espaçonaves, as sondas espaciais, os foguetes e os satélites artificiais passaram a coletar informações a respeito de outros corpos celestes, dentro e fora do Sistema Solar. Os satélites transferiram o Capitalismo para o espaço, por meio do uso comercial de informações coletadas e transmitidas do espaço, permitindo uma verdadeira revolução nas comunicações terráqueas.

\section{Revolução Cubana e Guerra de Guerrilha}

Além de ter recrudescido a Guerra Fria na América Latina, a Revolução Cubana (1959-1960), ao implantar o socialismo, pela primeira vez, em um país do subcontinente, acabou por criar um modelo alternativo ao modelo de desenvolvimento capitalista autônomo (nacionalista), que já fora tentado por figuras como Getúlio Vargas em passado recente. Aliás, no início da década de 1960, este modelo se mostrava profundamente contraditório, já que o Capitalismo entrara, definitivamente, na era da internacionalização.

Os líderes da Revolução Cubana, especialmente Fidel Castro e Che Guevara, reavivaram a possibilidade de um projeto socialista no subcontinente - esperança que se estiolara com os sucessivos fracassos das esquerdas latinoamericanas, no que se poderia chamar de "revoluções inacabadas" 15 ou "abortadas". Além disso, por causa do sucesso da estratégia no próprio solo cubano, a teoria do "foco revolucionário" apresentou-se como a verdadeira opção para as esquerdas latino-americanas, diante da "política das frentes" com as "burguesias nacionais", ou de qualquer outro modelo que viesse de Moscou ou de Pequim. Afinal, os barbudos haviam triunfado na luta contra a ditadura de Fulgêncio Batista, apesar de este verdadeiro títere ianque contar com forte apoio militar norte-americano. Como conseqüência, o movimento guerrilheiro - urbano e rural - explodiu em toda a América Latina e, por ironia do destino, foi em um deles, na Bolívia, que Che Guevara foi assassinado em 1967, transformando-se em verdadeiro ícone da romântica juventude revolucionária.

\section{Descolonização Africana e Asiática}

Como se sabe, a África foi, juntamente com a Ásia, o principal alvo do neo-colonialismo. ${ }^{16}$

A luta das nações africanas contra a dominação estrangeira se recrudesceu no contexto da Guerra Fria e, portanto, contou com a exacerbação da

\footnotetext{
15 Título de um livro de Fals Borda (1979).

16 Assim foi denominado o furor imperialista europeu, norte-americano e japonês do século XIX e primeira metade do século XX, para diferenciar-se do colonialismo dos inícios dos tempos modernos (séculos XVI e XVII).
} 
violência, já que as disputas locais (às vezes intertribais) eram alimentadas por armas sofisticadas, oferecidas por um dos dois grandes da bipolaridade política.

Em alguns momentos a Guerra Fria chegou a esquentar, como foi o caso da Guerra do Congo, em que as duas superpotências chegaram a se confrontar diretamente. Aí foi assassinado primeiro ministro Patrice Lumumba, considerado como o primeiro mártir da luta anticolonialista do continente africano. A criação da Organização da Unidade Africana, em 1963, apontava para uma superação do nacionalismo na própria luta pela independência dos países africanos.

A descolonização de países asiáticos encontra bons exemplos na China, na Coréia do Norte e no Vietnã. A primeira, após a revolução nacionalista do Dr. Sun Yat Sen, encontraria seu caminho fora do Estado Burguês, com a vitória da Grande Marcha de Mao-Tsé-Tung e a implantação do socialismo naquele verdadeiro continente do Extremo Oriente.

Apesar do alto preço de uma "guerra localizada" e da divisão do país em Norte e Sul, em 1954, a Coréia saiu da órbita do imperialismo ocidental.

Quanto ao Vietnã, é sobejamente conhecida sua história de lutas. Em 1954, o país se libertara, mas, também sob o preço da divisão em Vietnã do Norte e Vietnã do Sul. Certamente, se a bipolaridade da Guerra Fria tivesse continuado, todos os países do mundo caminhariam para a divisão em "do Norte" e "do Sul": os primeiros absorvidos pelo "socialismo real" e os segundo sugadas para a órbita do Capitalismo norte-americano. Ho-ChiMInh fora o líder da libertação vietnamita do norte e se tornaria um dos ícones da juventude de década. Várias investidas do norte, aliado com as frentes de libertação do sul, infringiram fragorosas derrotas ao governo de Saigon. A partir de 1964, os Estados Unidos resolveram interferir diretamente no conflito e atacaram o Vietnã do Norte em 1964. De nada adiantou a escalada então iniciada, com o desembarque maciço de tropas norte-americanas em solo vietnamita. Em 1968, a ofensiva Tet o povo vietnamita infringiu pesadas derrotas ao exército mais poderoso do planeta. Dez anos depois do início da "escalada", em 1965, os Estados Unidos saíram derrotados do Sudeste Asiático, com a entrada dos vietcongs em Saigon. O montante de sacrifício material e humano que custou ao país, com uma das guerras mais sangrentas do século XX, transformou o Vietnã num emblema da luta contra os impérios, por mais poderosos que eles sejam. 


\section{Cortinas Rasgadas e a Primavera de Praga}

Apesar de toda a impressão de unidade e homogeneidade, os monólitos de um lado e de outro da bipolaridade política apresentavam rachaduras. Do lado da "Cortina de Dólar", o gigante norte-americano, apresentava rachaduras internas, apesar de seu estupendo crescimento econômico e social - seu PIB chegara a um trilhão de dólares, com uma renda familiar ultrapassado os 20.000; um em cada dois norte-americanos concluía o curso secundário e um em cada dez, o superior. Internamente, nenhuma força estatal conseguia calar o grito da população negra (22,4 milhões), nem do clamor da guerra contra a guerra (do Vietnã). Emblematicamente, Martin Luther King, o maior líder da luta em defesa dos direitos dos negros, foi assassinado em 1968. E, para se compreender o tamanho da tragédia norte-americana, cinco anos antes tombara, em Dallas o próprio Presidente da República, John F. Kennedy, e, dois meses depois do líder negro, cairia, também crivado de balas, Robert Kennedy, potencial Presidente do país. Além disso, paises, do mesmo bloco, como a França, nem sempre apoiavam as políticas norte-americanas, chegando até mesmo à sua contestação.

O mesmo ocorria do lado da "Cortina de Ferro" e o caso mais emblemático foi o da Tchecoslováquia, com o que ficou conhecido como a "Primavera de Praga". Duas décadas antes os chineses, que conquistaram o poder sem o apoio expressivo de Moscou, deram os primeiros sinais de indocilidade em relação às orientações emanadas de Moscou. Em 1960, Tito, na Iugoslávia, que também tomara o poder "sozinho", contestou a unidade de direção de Moscou. As demais nações do Leste Europeu tinham de se dobrar a força da URSS, pois o Exército Vermelho fora fator determinante para a vitória na II Guerra Mundial: Alemanha Oriental (1949), Bulgária (1946), Tchecoslováquia (1948), Polônia (1947) e Romênia (1947).

Em alguns momentos, Kruschev fizera a balança da hegemonia mundial pender para o lado soviético. Numa cartada de manga, tentaram instalar, secretamente, foguetes de alcance médio, portando ogivas nucleares, em Cuba. O mundo esteve à beira de uma terceira conflagração mundial em 1962, quando o governo de John Kennedy, tendo descoberto a manobra, ameaçou reação. Fracassos na política internacional e rasgos na "Cortina de Ferro" precipitaram a queda de Kruschev, em 1964. É que, além ruptura sino-soviética (oficializada em 20 de julho de 1963) e das tendências maoístas albanesas, Nicolae Ceausescu, da Romênia, iniciara uma aproximação com o Ocidente, dado seu peso econômico no COMECOM, sem ter uma compensação proporcional no "mercado" político e econômico comunista. Já a Tchecoslováquia, antes de se tornar comunista, tivera uma forte tradição democrática e parlamentar. Também bafejada pelos bons ventos do desenvolvimento industrial, acomodara-se, e 
modo desajeitado ao stalinismo de Antonin Novotny. Com sua queda e a ascensão de Alexander Dubcek, o país tenta recuperar sua tradição democrática e sua economia abalada. A idéia da recuperação democrática e econômica da Tchecoslováquia, especialmente afastando-a de seus vícios stalinistas, não significava o distanciamento do campo socialista. No entanto, o Kremlin, mesmo percebendo esta fidelidade aos princípios socialistas, via as aberturas do país como um perigo de abertura para o Ocidente. A intervenção militar soviética, em agosto de 1968, interrompeu a "Primavera de Praga" e re-incorporou a Tchecoslováquia ao bloco da URSS, não sem deixar seqüelas rachaduras internas, apesar do "silêncio obsequioso" dos partidos comunistas de todo o mundo. Milan Kundera, com seus romances, especialmente com $A$ insustentável leveza do ser, pintou um painel crítico dos mais contundentes da invasão do país pelos tanques de Moscou.

\section{Razão jovem, Utopia Revolucionária e mundo alternativo.}

Contestação, rebeldia, resistência e revolução foram palavras de ordem da década de 1960. O denominador comum era o advérbio "não", dirigido a todas as estruturas, capitalistas ou socialistas, e cuja expressão máxima foi a negação radical de todas as negações: "É proibido proibir".

A expressão dessa postura contestatória se concretizou nos movimentos da juventude que, grosseiramente, se pode classificar em dois tipos: o movimento hippie (com a contracultura) e o movimento estudantil. Ambos exprimiam a rejeição do instituído, mas, cada um, a seu modo.

O movimento hippie foi à expressão radicalizada da contracultura, que era veiculada, também, pela música, pelo teatro, pelo cinema, pelas artes plásticas. A rejeição, aí, se dava pela negação de todas as convenções, no vestuário, no modo de se apresentar, nas saudações, na fuga para uma sociedade comunitária, nas "viagens" proporcionadas pelas drogas. Algumas vezes, convergiam com as ações dos grupos de jovens mais engajados politicamente, participando de marchas de protestos, como foi o caso das manifestações de defesa dos direitos dos negros e de resistência à Guerra do Vietnã. Milos Forman faz uma análise das mais expressivas da alienação ${ }^{17}$ hippie no filme Hair, inspirado na peça homônima que, além de ser uma contundente denúncia da guerra, constitui um verdadeiro manifesto da utopia hippie da "Era de Aquarius".

\footnotetext{
${ }^{17}$ Hoje, o uso o termo «alienação» para categorizar o comportamento dos hippies com relativo incômodo, porque ele deriva mais de nossa própria experiência, localizada no Brasil, do que de uma análise histórico-social mais isenta. Á época, os engajados politicamente, cobrávamos dos hippies brasileiros maior compromisso com a sociedade massacrada por uma ditadura militar do que com seu próprio bem estar. da Dietilamida de Ácido Lisérgico, simplesmente conhecido como.
} 
A inspiração desta parte da juventude vinha de Timothy Leary (19201996), o escritor e psicólogo norte-americano, que defendeu as virtudes terapêuticas e popularizou o consumo do LSD, ${ }^{18}$ que, na década de 1960 foi associado ao movimento psicodélico. ${ }^{19} \mathrm{O}$ movimento de oposição e fuga à/ da sociedade industrial, de retomada do contato com a natureza, propunha formas alternativas de vida e organização social e tudo isso embalado com muita música, muita cor e muito LSD e outras drogas, sem falar da inspiração do misticismo oriental (Budismo, Hinduísmo etc.). O festival de Woodstock Music and Art Fairinspirou outros eventos congêneres, por todo o mundo e, neles, as palavras de ordem eram "Make love, not war" (Faça amor, não faça a guerra) e "Peace and Love" (Paz e Amor). Tais pensamentos e a tônica do premiadíssimo filme Easy Rider ("Sem Destino"), de Dennis Hopper, foram contrariados em vários eventos psicodélicos, como, por exemplo, no festival de Altamont, em que a violência resultou em quatro mortes.

Não conformados com a "inconformidade alienada" dos hippies, uma boa parte da juventude, inspirada em Herbert Marcuse, da Escola de Frankfurt $^{20}$, em Fidel Castro, Che Guevara e Ho-Chi-Minh, propunha a tomada do poder pela juventude, por meio da rebelião armada e focalizada.

Os jovens que se enfastiavam no consumismo da riqueza debandaram para a opção hippie; os que se debatiam na escassez e na resistência às sanguinárias ditaduras optaram pela luta armada. Neste caso, era preciso criar outras Sierras Maestras ou outros Vietnãs.

De qualquer modo, eram duas utopias que, com suas diferenças, tinham o denominador comum de serem sustentadas por jovens e de contestarem todo o mundo instituído, fosse do lado burguês, fosse do lado socialista.

E estas utopias revolucionárias - revolucionárias, sim, porque queriam a substituição da ordem instalada por outro tipo de sociedade - alastraram-se por todo o Planeta, no universo dos dois projetos hegemônicos que digladiavam entre si pelo domínio do mundo.

\footnotetext{
18 A Lysergsäurediethylamid, ou dietilamida do ácido lisérgico, foi sintetizada, pela primeira vez em 1938, cujas propriedades alucinógenas foram descobertas pelo químico suíço Albert Hoffmann, em 1943.

19 Palavra composta de dois termos gregos (psiké $=$ mente e deloun $=$ sensorial) e que se refere às manifestações mentais que têm efeitos profundos na experiência consciente. $\mathrm{O}$ movimento de oposição e fuga à/da sociedade industrial, de retomada do contato com a natureza e tudo isso embalado com muita música, muita cor e muito LSD e outras drogas.

${ }^{20}$ Marcuse vinculou-se à Escola, mas sempre teve problemas com o seu «establishment», na medida em que sempre defendeu a politização da filosofia, melhor, a fusão de filosofia, teoria social e política. Em suma, Marcuse defendia a profunda interação entre teoria e prática e, no momento da rebelião estudantil, não hesitou em dar seu apoio inconteste, bem como não titubeou em criticar o imperialismo norte-americano no Vietnã. Acabou por se tornar no filósofo inspirador da rebelião da juventude.
} 


\section{CONSIDERAÇÕES FINAIS}

A esta altura, cabe enfatizar que, para sair do mero relato e conferir um fundamento político à discussão, é necessário responder, ainda que sumariamente, pelo menos, a duas questões:

a) Por que movimento jovem?

b) Por que se espalhou por todo o Globo, independentemente das opções políticas instituída?

Entendo o movimento de rebelião juvenil como um eco mais distante do longo conflito mundial, que ocupou quase toda a primeira metade do século XX. (1914-1945). Quando as autoridades prometiam e a maioria da população do mundo acreditava que o mundo não conheceria um conflito tão sangrento quanto fora a I Guerra (1914-1918), o curto e trágico entre guerras acabou por provocar um conflito muito mais violento e de proporções inimagináveis, a II Grande Guerra (1939-1945). Boa parte das sociedades européias havia perdido o melhor de sua juventude e o pessimismo insinuado em especulações filosóficas como o Existencialismo, logo após o primeiro conflito mundial, exacerbaram-se após o segundo. A possível flexibilização do pessimismo oferecido pelo crescimento econômico alcançado pelo Capitalismo e pelo Socialismo Real não conseguiu mitigar a crença na possibilidade de um terceiro conflito, no contexto da Guerra Fria. E houve momentos em que a guerra quase se esquentou... Ora, toda esta marcha da insensatez humana havia sido proporcionada pelos adultos, que sempre afirmaram que "os jovens de hoje, são os homens de amanhã". Toda esta proclamação sobre a necessidade da preparação dos jovens para o amanhã não "colava" mais, seja por, seu cunho sexista, seja pela concretude de irracionalidade adulta, que criara todas as instituições de um processo civilizatório, que se negava enquanto tal e que punha a humanidade na trilha da barbárie.

A juventude dos diversos países do mundo, por motivações imediatas as mais variadas, resolveram tomar o mundo em suas próprias mãos, tentando criar o que se poderia chamar de "poder jovem", isto é, a afirmação, hoje (não, amanhã) de seu poder.

Por trás dessas atitudes, está a proclamação de uma outra racionalidade, de uma "Razão Jovem", que se propõe como interpretação mais adequada do processo humano, seja tomando o poder concreto e fazendo dele um instrumento de construção de um outro projeto de civilização, seja construindo, paralelamente ao instituído, um outro mundo. A primeira proposta poderia ser classificada como revolucionária, porque visava à substituição de um projeto por outro: a segunda, poderia ser classificada apenas como uma altemativa ao mundo existente.

Outras racionalidades contra-hegemônicas emergiriam com mais força e se somariam à dos jovens, como a "Razão Feminina" e a "Razão Negra". Mas isto é tema para outro trabalho.

Não gostaríamos de encerrar estas reflexões sem uma curta palavra a respeito do movimento jovem no Brasil. 
Como é sobejamente conhecido, o Brasil sofreu um golpe militar em 1964, mas foi somente em 1968, com um golpe dentro do golpe, que a ditadura mostrou sua verdadeira face de violência e irracionalidade.

Como a juventude do Leste Europeu, que tinha de se engajar na luta contra a autocracia soviética, a juventude brasileira não tinha muito como optar pelo psicodelismo tanto por não viver o crescimento econômico das nações do Primeiro Mundo, quanto por se constituir na quase única alternativa de manifestação política. A ditadura extinguira os partidos e as outras formas tradicionais de representação política, afastando o estado da Sociedade e optando pela entrega do país ao capital estrangeiro. Resistir à ditadura, no Brasil, significava resistir ao "american way of life" e dar continuidade à mobilização propiciada pelo Estado Populista da década passada e, principalmente dos primeiros anos da de 60.

O mais curioso e, aparentemente contraditório, era que a ditadura recrudescia a internalização da Guerra Fria, pela luta entre esquerda e direita, no momento em que, internacionalmente, os Estados Unidos apregoavam o degelo das fronteiras ideológicas.

Em março de 1968, reprimindo uma manifestação da Frente Unida dos Estudantes do Calabouço, foi assassinado o secundarista Edson Luís de Lima Souto. Daí resultou uma série de mobilizações, que culminaram, em junho com a "passeata dos 100 mil", com palavras de ordem mais politizadas: "Abaixo a ditadura" e "O povo unido jamais será vencido". A solidariedade dos estudantes para com os operários de Osasco em greve reproduzia o ineditismo desta interação que ocorrera também na França. As greves de Contagem (MG), a atuação das organizações clandestinas, como a Ação Libertadora Nacional (ALN) e a Vanguarda Popular Revolucionária (VPR), para a obtenção de recursos para a resistência armada, as manifestações da Conferência Nacional dos Bispos Brasileiros (CNBB), demonstrando o aprofundamento do conflito Igreja/ Estado e da Ordem dos Advogados do Brasil (OAB), denunciando o "Estado de Exceção", denunciando o Etsado de Exceçil (OAB)(CNBB), demonstrando o aprofundamento do conflito Igreja/Estado, degelo das fronteiras id acabaram por desencadear a reação da extrema direita e o aprofundamento da ditadura.

A partir daí, a violência física e simbólica da ditadura se abateu sobre a juventude brasileira por cerca de mais de uma década e meia.

Não há dúvida de que as marcas do "romantismo revolucionário", atribuída por Marcelo Ridenti ${ }^{21}$ aos movimentos em que a juventude brasileira se engajou, acabaram por provocar a tragédia da vitória de uma ditadura que se prolongou por 21 anos.

${ }^{21}$ FERREIRA, J; DELGADO, L. A. N (Org.). (2003): O Brasil Republicano 4 - o tempo da ditadura: regime militar e movimentos sociais em fim de século XX, Rio de Janeiro, Civilização p. 133. 


\section{FUENTES}

Jornalista Zuenir Ventura (1988)

Entrevista a PAES SIMÕES, María Helena.

VEJA. Os anos 60: a década que mudou tudo. São Paulo: Abril, s/d (publicação editada em fascículos).

\section{SELECCIÓN BIBLIOGRÁFICA}

BORDA, Fals. (1977): Revoluções inacabadas na América Latina, São Paulo: Global, 1979.

DURKHEIM, Émile. As regras do método sociológico, Tradução Maria Isaura Pereira de Queiroz, São Paulo: Nacional.

FERREIRA, Jorge; DELGADO, Lucília de Almeida Neves, (org.). (2003): O Brasil Republicano 4 - O tempo da ditadura: regime militar e movimentos sociais em fins do século XX, Rio de Janeiro: Civilização Brasileira.

FUENTES, Carlos. (2008): Em 68: Paris, Praga e México, Tradução Ebréia de Castro Alves, Rio de Janeiro: Rocco.

MIGNOLO, Walter. (2003): Histórias locais/projetos globais: colonialidade, saberes subalternos e pensamento liminar, Tradução Solange Ribeiro de Oliveira, Belo Horizonte, Ed. UFMG.

PAES, María Helena Simões. A década de 60: rebeldia, contestação e repressão política. São Paulo: Ática

VENTURA, Zuenir (1988): 1968: o ano que não acabou. São Paulo: Círculo do Livro, 1988

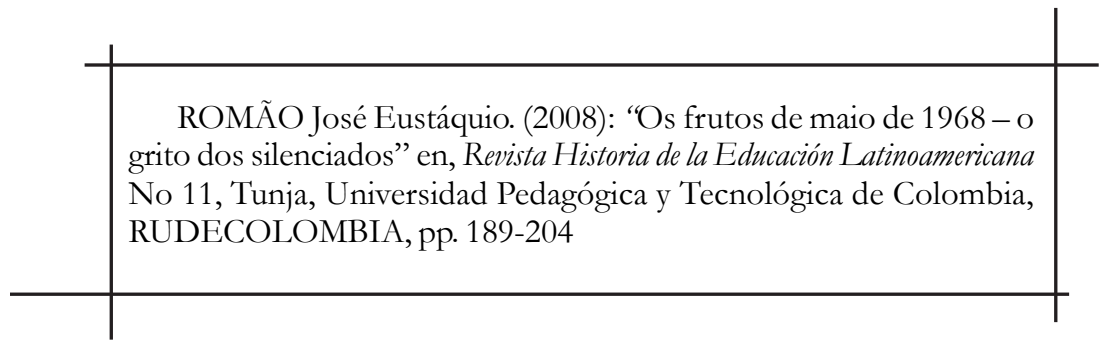

